\title{
Scaling behaviour of the global tropopause
}

\author{
C. Varotsos, M. Efstathiou, and C. Tzanis \\ Department of Applied Physics, University of Athens, Athens, Greece \\ Received: 27 June 2008 - Published in Atmos. Chem. Phys. Discuss.: 1 October 2008 \\ Revised: 11 December 2008 - Accepted: 16 December 2008 - Published: 28 January 2009
}

\begin{abstract}
Detrended fluctuation analysis is applied to the time series of the global tropopause height derived from the 1980-2004 daily radiosonde data, in order to detect longrange correlations in its time evolution.
\end{abstract}

Global tropopause height fluctuations in small timeintervals are found to be positively correlated to those in larger time intervals in a power-law fashion. The exponent of this dependence is larger in the tropics than in the middle and high latitudes in both hemispheres. Greater persistence is observed in the tropopause of the Northern than in the Southern Hemisphere. A plausible physical explanation of the fact that long-range correlations in tropopause variability decreases with increasing latitude is that the column ozone fluctuations (that are closely related with the tropopause ones) exhibit long range correlations, which are larger in tropics than in the middle and high latitudes at long time scales.

This finding for the tropopause height variability should reduce the existing uncertainties in assessing the climatic characteristics. More specifically the reliably modelled values of a climatic variable (i.e. past and future simulations) must exhibit the same scaling behaviour with that possibly existing in the real observations of the variable under consideration. An effort has been made to this end by applying the detrended fluctuation analysis to the global mean monthly land and sea surface temperature anomalies during the period January 1850-August 2008. The result obtained supports the findings presented above, notably: the correlations between the fluctuations in the global mean monthly land and sea surface temperature display scaling behaviour which must characterizes any projection.

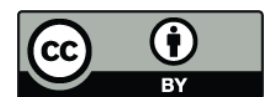

Correspondence to: C. Varotsos (covar@phys.uoa.gr)

\section{Introduction}

The location of the tropopause - the boundary between the troposphere and stratosphere - can be defined in a variety of ways, according to dynamic, thermal, and physico-chemical properties of the atmosphere (Hoinka, 1998; 1999; Reichler et al., 2003).

Conventionally, the tropopause is a thin layer separating the turbulently mixed troposphere (where temperature decreases with height) from the stably stratified stratosphere (with temperatures constant or increasing with height). The thermal tropopause is operationally defined as the lowest level at which the lapse rate decreases to $2^{\circ} \mathrm{C} / \mathrm{km}$ or less, provided also the average lapse rate between this level and all higher levels at intervals of $2 \mathrm{~km}$ does not exceed $2^{\circ} \mathrm{C} / \mathrm{km}$ (WMO, 1957). However, a number of observational studies suggest that the tropopause is a transition zone, which is also marked by changes in the chemical composition of the atmosphere.

Precise knowledge of the temporal and spatial structure of this transition zone is necessary in order to evaluate the exchange of mass, water, and chemical constituents between the troposphere and the stratosphere (Allen et al., 2008; Varotsos et al., 1995, 2004). Furthermore, under the physicochemical conditions prevailed in the upper troposphere-lower stratosphere, several gas-solid reactions involving chlorine and bromine can directly or indirectly cause ozone destruction, depending on the variability of the solid particle properties (e.g. the conductivity, dielectric constant) with air temperature and pressure (Kostopoulos et al. 1975; Varotsos, 1978, 1981).

Changes in tropopause height may be a useful "fingerprint" of human effects on climate. That is because the tropopause height should do the following: (1) increase in response to warming of the troposphere and cooling of the stratosphere caused by increases in well-mixed greenhouse gases; (2) increase due to cooling of the stratosphere induced

Published by Copernicus Publications on behalf of the European Geosciences Union. 
by stratospheric ozone depletion (Chandra and Varotsos, 1995; Varotsos, 1989, 2002, 2004; Varotsos and Cracknell, 1993, 1994); (3) decrease after the stratospheric warming and tropospheric cooling resulting from massive volcanic eruptions (Kondratyev and Varotsos, 1995 a, b, c).

The height of the 100-hPa level is a good estimate for the tropopause height in the tropics, the $200-\mathrm{hPa}$ level is appropriate in the midlatitudes, and the $300-\mathrm{hPa}$ level is a good estimate for both polar regions. The temperature at $100 \mathrm{hPa}$ represents a good approximation to the global tropopause temperature (Hoinka 1998).

Of particular interest is the tropical tropopause, since it is widely accepted that most water vapor (primary greenhouse gas - GHG) enters the stratosphere here; hence, tropical tropopause conditions have a strong influence on the stratospheric water vapor distribution. The large vertical temperature gradients both above and below the tropical tropopause act as a strong constraint on the size of the tropopause height changes that can be caused by predominantly tropical modes of variability (such as El Nino/Southern Oscillation - ENSO). In contrast, ozone- and GHG-induced cooling of the stratosphere tend to be largest in high latitudes at both hemispheres (Cortesi et al., 2007; Efstathiou et al., 2003; Gernandt et al., 1995; Kondratyev et al., 1994; Sausen and Santer, 2003).

In a recent study Seidel and Randel (2006) examined the global tropopause variability on synoptic, monthly, seasonal, and multidecadal timescales by applying conventional statistical tools on the 1980-2004 radiosonde data. They found that the association of tropopause height and stratospheric temperature trends, together with the presence of a significant quasi-biennial oscillation signal in tropopause height, suggests that at these lowest frequencies the tropopause is primarily coupled with stratospheric temperatures. They have finally reached to the conclusion that the long-term changes in the tropopause (considered as an indicator of climate change) may carry less information about changes throughout the vertical temperature profile than has been suggested by previous studies using global climate models.

In this context, Varotsos and Kirk-Davidoff (2006) analysing global tropospheric temperature observations have come to the conclusion that the correlation function of the tropospheric temperature time series decays more slowly than the corresponding exponential one and the departure from the exponential fit becomes more pronounced towards the low frequencies. Moreover, they noticed that the determination of the power spectrum is hampered by large statistical uncertainties if one goes to low frequencies e.g. the QBO and the 11-yr solar cycle. In an attempt to overcome this difficulty Varotsos and Kirk-Davidoff (2006) suggested that the pattern of the decay of autocorrelation with increasing time lag can be efficiently obtained using detrended fluctuation analysis (DFA) introduced by Peng et al. (1994), which transforms this decay with increasing lag into an increase in noise amplitude as time scale increases, a measure that is less sensitive to statistical errors (Talkner and Weber, 2000).

The present study deals with the specific features of the temporal fluctuations of the global tropopause height and discusses in detail whether the tropopause height fluctuations at different times are positively correlated exhibiting thus persistent long-range correlations. This will be done by applying the modern technique of DFA to the data used in Seidel and Randel (2006).

\section{Methodology and analysis}

\subsection{The data set}

Our analysis is based on all available radiosonde observations from 100 stations (listed in Table 1 of Seidel and Randel, 2006) obtained from the Integrated Global Radiosonde Archive at the NOAA National Climatic Data Center (NCDC). These stations were selected on the basis of the length and completeness of their archived daily data record, with an aim towards coverage of the tropics (centred on the equator), Northern and Southern Subtropics (centred on $27.5^{\circ}$ latitude), midlatitude (centred on $51.4^{\circ}$ latitude), and polar (centred on $77.1^{\circ}$ latitude) zones.

The monthly anomaly time-series of the tropopause height (in global and zonal bands) during the period 1980-2004 were provided by Dr. Seidel, after personal communication. Monthly anomaly time series were computed by subtracting the mean seasonal cycle from the monthly means (an extensive description is given by Seidel and Randel, 2006).

\subsection{The analytical method}

As mentioned above Seidel and Randel (2006) applied wellknown statistical tools on the same time-series and discussed the dominating components, annular mode, QBO, ENSO etc. The purpose of the present paper is to employ a recently developed technique to detect long-range correlations in the same time-series.

One of the principal problems of the techniques employed for a time series analysis is that the direct calculation of the autocorrelation function is usually not the best way to distinguish among different decay patterns at long lags, due to noise superimposed on the data (Stanley, 1999; Kantelhardt et al., 2002). As has been mentioned in the Introduction, the pattern of the autocorrelation decay with increasing time lag can be efficiently obtained using DFA.

The sequential steps of DFA, which has proved useful in analysing a large variety of complex systems with selforganizing behaviour (e.g. Peng et al., 1994; Weber and Talkner, 2001; Chen et al., 2002; Varotsos, et al., 2000, 2003, 2005, 2006), are briefly, as follows (a detailed description is given by Varotsos et al., 2007): 
1) We build a new time series, by integrating over time the deseasonalized time series of tropopause height (Z). In details, to integrate the data, we calculate the fluctuations of the $\mathrm{N}$ observations $\mathrm{Z}(\mathrm{i})$ from their mean value $\mathrm{Z}_{\text {ave }}$, notably: $\mathrm{Z}(\mathrm{i})-\mathrm{Z}_{\text {ave }}$. Therefore, the new time series (the integrated time series), is consisting of the following points:

$$
\begin{aligned}
& y(1)=\left[Z(1)-Z_{\text {ave }}\right], \quad y(2)=\left[Z(1)-Z_{\text {ave }}\right]+ \\
& {\left[Z(2)-Z_{\text {ave }}\right], \ldots, \quad y(k)=\sum_{i=1}^{k}\left[Z(i)-Z_{\text {ave }}\right]}
\end{aligned}
$$

The integration magnifies the non-stationarity nature of the original data, degrades the noise level, and transforms the original time series to a new one of random walk having the values of the original time series as increments. Apparently, the integrated time series preserves variability characteristics of the original time series (Kantelhardt et al., 2002).

2) We split the integrated time series into non-overlapping windows (segments) of equal length, $n$. In each segment, a least squares line is fitted to the data. The least squares line in each segment may be replaced with a polynomial curve of order $l$, in which case the method is referred to as DFA- $l$.

3) Let $y_{n}(k)$ be the $y$ coordinate of the straight line segments. We proceed to the subtraction of the local trend, in each segment and to the calculation, for a given segment size $n$, of the root-mean-square fluctuation function:

$$
F(n)=\sqrt{\frac{1}{N} \sum_{k=1}^{N}\left[y(k)-y_{n}(k)\right]^{2}}
$$

4) This computation is repeated over all time scales (segment size) to provide a relationship between $F(n)$, the average fluctuation as a function of segment size, and the segment size $\mathrm{n}$. In the presence of scaling, fluctuations can be characterized by the scaling exponent $\alpha$, determined as the slope of the graph of $\log F(n)$ versus $\log (n)$.

The fluctuation exponent $\alpha$ indicates the presence of scaling (self-similarity), i.e. the fluctuations in small segments are related to the fluctuations in larger segments in a power-law fashion and then the power spectrum function $S(f)=1 / f^{\beta}$, with $\beta=2 \alpha-1$. It is clear that for stationary time series, the power spectrum is the Fourier transform of the autocorrelation function, and the following relationship between the autocorrelation exponent $\gamma$ and the power spectrum exponent $\beta$ holds: $\gamma=1-\beta=2-2 \alpha$, where $\gamma$ is defined by the autocorrelation function $C(\tau)=1 / \tau^{\gamma}$ ( $\tau$ is a time lag) and $0<\gamma<1$ (Talkner and Weber, 2000; Chen et al., 2005). For uncorrelated data, the scaling exponent is $\alpha=0.5$. An exponent $\alpha \neq 0.5$ in a certain range of $n$ values implies the existence of long-range correlations in that time interval. If $\alpha<0.5$, power-law anticorrelations are present (antipersistence). When $0.5<\alpha \leq 1.0$, then persistent long-range powerlaw correlations prevail (the case $\alpha=1$ corresponds to the so-called $1 / f$ noise).

\section{Discussion and results}

As has been mentioned above, the purpose of this paper is the investigation of the time scaling of the tropopause height $(\mathrm{Z})$ fluctuations over the tropical, subtropical, middle and high latitudinal zones of both hemispheres.

Inspection of each of the time series of the monthly anomalies of the tropopause height for the globe and in seven 25.7-degree latitude bands for 1980-2004 shows that each of them is apparently non-stationary, and includes both periodic and aperiodic fluctuations. A thorough analysis of numerous publications reveals that these non-stationarities often conceal the existing correlations in the examined data and therefore, in the light of this difficulty, a special analytical tool must be employed.

Let's start the analysis of the time series of the monthly anomalies of tropopause height (Z) for the tropics (see Fig. 9 in Seidel and Randel, 2006) by asking if it exhibits longrange correlations (i.e. the $Z$ value in a given instant has any correlation with the $\mathrm{Z}$ at a later time). The motivation to address this question stems from the observation that many environmental quantities are characterized by long-range dependence (their values remain residually correlated with one another, even after many years).

In our analysis we have used the monthly anomalies (detrended and deseasonalised) of tropopause height to reliably gain insight into this problem, notably, to avoid obscuring a possible scaling behaviour from the long-term trend and various frequency peaks induced from the well known cycles (Steinbrecht et al., 2006; Hu et al., 2001).

We next analyze the data of the monthly anomalies of tropopause height $(\mathrm{Z})$ for the tropics using DFA-1 for the reasons explained above. The results are depicted in Fig. 1 , where a $\log -\log$ plot of the root-mean-square fluctuation function $F_{d}(\Delta t)=F(n)$ is shown. Since, $\alpha=0.97( \pm 0.04)$ for latitude $0^{\circ}$, we conclude that $\mathrm{Z}$ fluctuations over the equator exhibit persistent long-range correlations ( $1 / f$ noise-like) for the interval time ranging from about 4 months to about 6 years (statistically significant). Note that the derived $1 / \mathrm{f}$ noise-like behavior of the tropical tropopause is of particular interest, because most water vapor enters the stratosphere here. It is also worth noting that the long-range correlations obtained do not signify the presence of cycles with definite periodicities (i.e. as described in Camp et al., 2003), but 

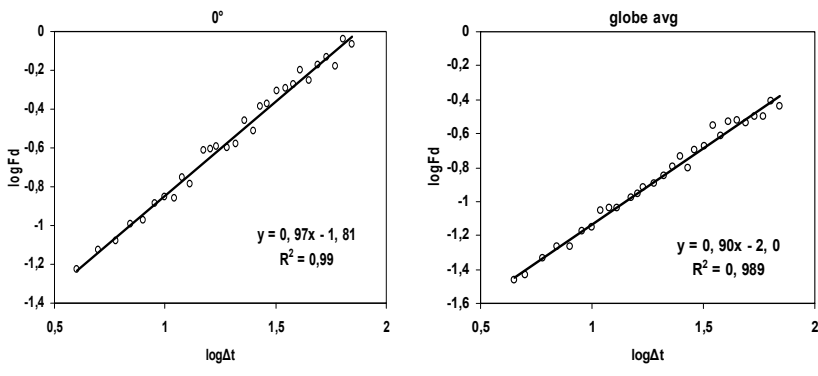

Fig. 1. Log-log plot of the tropopause height $(\mathrm{Z})$ root-meansquare fluctuation function $\left(F_{d}(\Delta t)\right)$ versus temporal interval $\Delta t$ (in months) for detrended and deseasonalized monthly $\mathrm{Z}$ values, observed by the radiosonde network over the equator and the globe during 1980-2004.

rather the existence of dynamical links between long and short time-scale behavior.

Subsequently, we apply the above-mentioned analytical method to the time series of the monthly anomalies of tropopause height $(\mathrm{Z})$ for the globe. The results obtained are depicted in Fig. 1, where, since $\alpha=0.90( \pm 0.04)$, strong persistence of the globe average $\mathrm{Z}$ fluctuations is observed and the interval time ranges from 4 months to 6 years (ENSO), approximately.

In the following, we examine the subtropics, the midlatitude and high latitude zones, and specifically the $\mathrm{Z}$ data for six 25.7-degree latitude bands of both hemispheres during 1980-2004. By employing the DFA-1, the analysis of the deseasonalised and detrended $\mathrm{Z}$ data shows that, once again, persistent long-range correlations exist in all latitude bands of both hemispheres. According to Fig. 2, the correlations in $\mathrm{Z}$ fluctuations eventually exhibit increasing memory going from the high to the low latitudes and the memory is stronger in the Northern Hemisphere than in the Southern Hemisphere.

It should be emphasized that a plausible tool to test the above-discussed results, is to apply to the same $\mathrm{Z}$ time series the DFA- $l$ method. The results obtained from the DFA- $l$ analysis did not show any substantial deviations from those seen in Figs. 1 and 2. To understand, however, the factors determining the long-range persistence in the tropopause height, we investigated whether this persistence stems from the values of $Z$ by themselves and not from their time evolution. To this end, we applied DFA-1 to randomly shuffled $Z$ data over the tropics. The result obtained from this analysis is $\alpha=0.51 \pm 0.02$ and hence we have reached to the conclusion that this persistence exclusively stems from the sequential ordering of the $\mathrm{Z}$ values and is not a result of the distribution of the $\mathrm{Z}$ values. It would be worthwhile to mention that similar results were also obtained for the $\mathrm{Z}$ time series over the subtropics, middle and polar latitudes in both hemispheres.
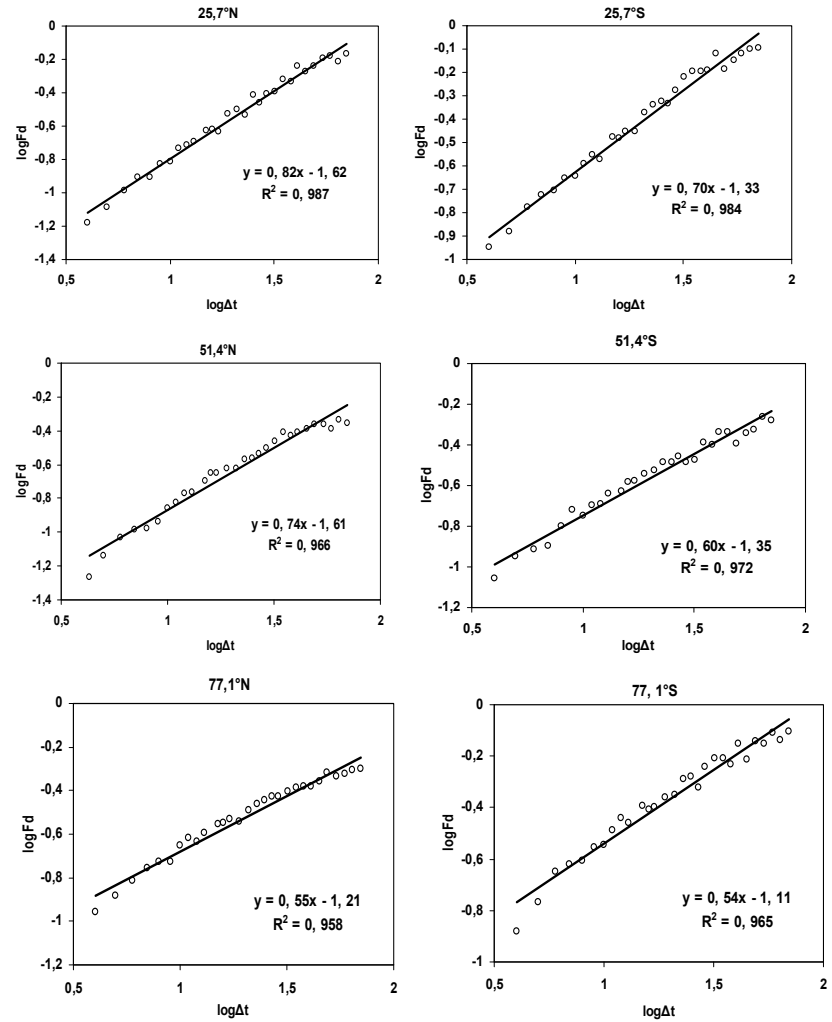

Fig. 2. Log-log plot of the tropopause height $(\mathrm{Z})$ root-meansquare fluctuation function $\left(F_{d}(\Delta t)\right)$ versus temporal interval $\Delta t$ (in months) for detrended and deseasonalized monthly $\mathrm{Z}$ values, observed by the radiosonde network over the tropics, middle and high latitudes of the Northern and Southern Hemispheres during 1980 2004.

In summary, the $\mathrm{Z}$ fluctuations over the tropics, subtropics, middle and polar latitudes of both hemispheres, as well as globally, exhibit persistent long-range correlations for all time lags between about 4 months- 6 years. Over the tropics, this persistence becomes stronger approaching the 1/f mode.

From the viewpoint of the plausible explanation of this finding, it would be worthwhile to recall that greater persistence is, in general, a result of either stronger positive feedbacks or larger inertia. In fact, Varotsos and KirkDavidoff (2006) analyzing global column ozone data during 1978-2004 have come to the conclusion that the column ozone fluctuations (strongly associated with tropopause variability) exhibit long range correlations that are larger in tropics than in the mid-latitudes and high latitudes at long time scales. They have also suggested that, on average, greater persistence is observed in the column ozone variability (that is strongly associated with the tropopause variability) of the Northern than in the Southern Hemisphere. Indeed, Fig. 2 shows that greater persistence is observed in the tropopause of the Northern than in the Southern Hemisphere and decreases with increasing latitude. 
Bearing in mind that long-range dependence and long memory are synonymous notions, the above-said finding is equivalent to that the global tropopause height exhibits long memory, associated thus with fractal behaviour.

An extreme complexity of the problem discussed is that it is desirable to explain the cause that generates the long memory effect in column ozone, tropopause properties, etc and then to proceed to the estimation of the consequences. Unfortunately, the present stage of relative studies can be considered not more than initial and preliminary. What is missing is some kind of theory for what the long range correlations in tropopause height ought to be.

Despite these circumstances, to reliably gain insight into this problem, the next step would be to repeat the analysis on a range of GCMs, and see if they have any meaningful differences among each other, and whether the above-mentioned results help to discriminate between models whose statistics show more or less fidelity to the real statistics. At present, if one could show that the decay in autocorrelation of the tropopause height was clearly connected to some aspect of model behavior that we care about (climate sensitivity for instance) that would make this a really useful result.

For this purpose, we have used the mean monthly land and sea surface temperature (LSST) anomalies derived from the datasets of the Climatic Research Unit (http://www.cru. uea.ac.uk/cru/data/temperature/), during the period January 1850-August 2008. To make a dataset with global coverage, which includes the coastal and island grid boxes, the land and marine data were blended into a combined average (see Jones et al., 2001; Rayner et al., 2006).

The DFA method, applied to the above-mentioned timeseries of the global mean monthly LSST anomalies (Fig. 3a) revealed strongly persistent long-range power-law correlations, with scaling exponent between 0.86 , for all time lags between 4 months and 39 years (Fig. 3b). The strong persistence found signifies that the fluctuations in LSST anomalies, from small time intervals to larger ones (up to 39 years) are positively correlated in a power-law fashion. This result suggests that the correlations between the fluctuations in LSST anomalies do not obey the classical Markov-type stochastic behaviour (exponential decrease with time), but display more slowly decaying correlations. The latter conclusion is consistent with the recent predictions of climate models and theoretical expectations, according to which the upper troposphere should be warming faster than the surface. At the tropical region, in particular, cooling of the tropical tropopause is a dynamical result of tropospheric convection, which in turn partially depends upon sea surface temperatures.

We finally investigated whether the above discussed persistence stems from the values of LSST anomalies by themselves and not from their time evolution. For instance, we applied DFA to randomly shuffled data of the LSST anomalies and the exponent obtained is $\alpha=0.53 \pm 0.01$. Thus, the "long memory" in the time series of the LSST anomalies
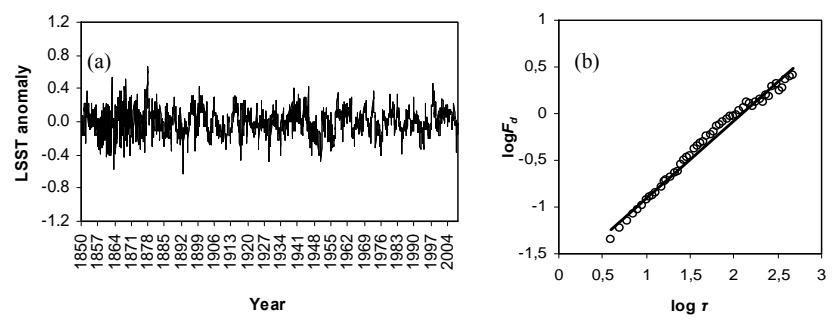

Fig. 3. (a)The time-series of the detrended and deseasonalized global mean monthly LSST anomalies, during January 1850August 2008. (b) The DFA-function, in log-log plot, for the time series shown in (a). The best linear fit equation is $y=0.86 \times-1.77$ $\left(R^{2}=0.98\right)$

stems from their time evolution and is not a result of their values distribution (Varotsos 2005).

\section{Conclusions}

The principal conclusion drawn from the above-mentioned analysis is that the tropopause height exhibits scaling behaviour. More specifically, the global tropopause height fluctuations in small time-intervals are found to be positively correlated to those in longer time intervals in a power-law fashion. The exponent of this dependence is larger in the tropics than in the middle and high latitudes in both hemispheres. In addition, sufficiently greater persistence is observed in the tropopause of the Northern than in the Southern Hemisphere. The scaling behaviour in tropopause height is a feedback of the scaling behaviour in column ozone suggested earlier (Varotsos and Kirk-Davidoff, 2006).

This property of the existing long memory in the tropopause height variability (assumed as fingerprint of human effects on climate), would increase the reliability of the existing long-term climate and atmospheric dynamics modelling, a subject on which special emphasis has been recently placed (Dameris et al., 2005; Ebel, 2001; Kondratyev and Varotsos, 1996, 2001; Reid et al., 1994, 1998). In this context, the application of the DFA method to the time-series of the global mean monthly land and sea surface temperature anomalies during the period January 1850-August 2008, revealed persistent long-range power-law correlations, for all time lags between 4 months and 39 years, which stem from the time evolution the land and sea surface temperature anomalies and not from their values distribution.

Edited by: M. Dameris 


\section{References}

Allen, G., Vaughan, G., Bower, K. N., Williams, P. I., Crosier, J., Flynn, M., Connolly, P., Hamilton, J. F., Lee, J. D., Saxton, J. E., Watson, N. M., Gallagher, M., Coe, H., Allan, J., Choularton, T. W., and Lewis, A. C.: Aerosol and trace-gas measurements in the Darwin area during the wet season, J. Geophys. Res.-Atmos., 113(D6), D06306, doi:10.1029/2007JD008706, 2008.

Camp, C. D., Roulston, M. S., and Yung, Y. L.: Temporal and spatial patterns of the interannual variability of total ozone in the tropics, J. Geophys. Res., 108(D20), No. 4643, 25 October, doi:10.1029/2001JD001504, 2003.

Chandra, S. and Varotsos, C. A.: Recent trends of the total column ozone - implications for the Mediterranean region, Int. J. Remote Sens., 16, 1765-1769, 1995.

Chen, Z., Ivanov, P. C., Hu, K., and Stanley, H. E.: Effect of nonstationarities on detrended fluctuation analysis, Phys. Rev. E., 65, 041107, doi:10.1103/PhysRevE.65.041107, 2002.

Chen, Z., Hu, K., Carpena, P., Bernaola-Galvan, P., Stanley, H. E., and Ivanov P. C.: Effect of nonlinear filters on detrended fluctuation analysis, Phys. Rev. E., 71, 011104, doi:10.1103/PhysRevE.71.011104, 2005.

Cortesi, U., Lambert, J. C., De Clercq, C., Bianchini, G., Blumenstock, T., Bracher, A., Castelli, E., Catoire, V., Chance, K. V., De Mazière, M., Demoulin, P., Godin Beekmann, S., Jones, N., Jucks, K., Keim, C., Kerzenmacher, T., Kuellmann, H., Kuttippurath, J., Iarlori, M., Liu, G.Y., Liu, Y., McDermid, I. S., Meijer, Y. J., Mencaraglia, F., Mikuteit, S., Oelhaf, H., Piccolo, C., Pirre, M., Raspollini, P., Ravegnani, F., Reburn, W. J., Redaelli, G., Remedios, J. J., Sembhi, H., Smale, D., Steck, T., Taddei, A., Varotsos, C., Vigouroux, C., Waterfall, A., Wetzel, G., and Wood, S.: Geophysical validation of MIPAS-ENVISAT operational ozone data, Atmos. Chem. Phys., 7, 4807-4867, 2007, http://www.atmos-chem-phys.net/7/4807/2007/.

Dameris, M., Grewe, V., Ponater, M., Deckert, R., Eyring, V., Mager, F., Matthes, S., Schnadt, C., Stenke, A., Steil, B., Bruhl, C., Giorgetta, and M. A.: Long-term changes and variability in a transient simulation with a chemistry-climate model employing realistic forcing, Atmos. Chem. Phys., 5, 2121-2145, 2005, http://www.atmos-chem-phys.net/5/2121/2005/.

Ebel, A.: Evaluation and reliability of meso-scale air pollution simulations, Lect. Notes Comput. Sc., 2179, 255-263, 2001.

Efstathiou, M. N., Varotsos, C. and Kondratyev, K.Y.: An estimation of the surface solar ultraviolet irradiance during an extreme total ozone minimum, Meteorol. Atmos. Phys., 68(3-4), 171$176,1998$.

Efstathiou, M. N., Varotsos, C., Singh, R. P., Cracknell, A. P., and Tzanis, C.: On the longitude dependence of total ozone trends over middle-latitudes, Int. J. Remote Sens., 24, 13611367, 2003.

Gernandt, H., Goersdorf, U., Claude, H. and Varotsos, C. A.: Possible impact of polar stratospheric processes on mid-latitude vertical ozone distributions, Int. J. Remote Sens., 16, 1839-1850, 1995.

Hoinka, K. P.: Statistics of the Global Tropopause Pressure, Mon. Weather Rev., 126, 12, 3303-3325, 1998.

Hoinka, K. P.: Temperature, Humidity, and Wind at the Global Tropopause, Mon. Weather Rev., 127 (10), 2248-2265, 1999.

Hu, K., Ivanov, P. C., Chen, Z., Carpena, P., and Stanley, H. E.: Effect of trends on detrended fluctuation analysis, Phys. Rev. E,
64, 011114, 2001.

Jones, P. D., Osborn, T. J., Briffa, K. R., Folland, C. K., Horton, E. B., Alexander, L. V., Parker, D., and Rayner, N. A.: Adjusting for sampling density in grid box land and ocean surface temperature time series. J. Geophys. Res., 106, 3371-3380, 2001.

Kantelhardt, J. W., Zschiegner, S. A., Koscielny-Bunde, E., Havlin, S., Bunde, A., and Stanley, H. E.: Multifractal detrended fluctuation analysis of nonstationary time series, Physica A, 316(1-4), 87-114, 2002.

Kondratyev, K. Y., Varotsos, C. A., and Cracknell, A. P.: Total ozone amount trend at St-Petersburg as deduced from NIMBUS7 TOMS observations, Int. J. Remote Sens., 15, 2669-2677, 1994.

Kondratyev, K. Y. and Varotsos, C. A.: Volcanic eruptions and global ozone dynamics, Int. J. Remote Sens., 16, 1887-1895., 1995a.

Kondratyev, K. Y. and Varotsos, C. A.: Atmospheric ozone variability in the context of global change, Int. J. Remote Sens., 16, 1851-1881, 1995b.

Kondratyev, K. Y. and Varotsos, C.: Atmospheric greenhouse effect in the context of global climat change. Nuovo Cimento della Societa Italiana di Fisica C-Geophysics and Space Physics, 18, 123-151, 1995c.

Kondratyev, K. Y. and Varotsos, C. A.: Global total ozone dynamics - Impact on surface solar ultraviolet radiation variability and ecosystems 1. Global ozone dynamics and environmental safety, Environ. Sci. Pollut. Res., 3, 153-157, 1996.

Kondratyev, K. Y. and Varotsos, C. A.: Global tropospheric ozone dynamics - Part II: Numerical modelling of tropospheric ozone variability - Part I: Tropospheric ozone precursors, Environ. Sci. Pollut. Res., 8(2), 113-119, 2001.

Kostopoulos, D., Varotsos, P. A., and Mourikis, S.: Conductivity of crystalline NaI., Can. J. Phys., 53, 1318-1320, 1975.

Peng, C. K., Buldyrev, S. V., Havlin, S., Simons, M., Stanley, H. E., and Goldberger, A. L.: Mosaic organization of DNA nucleotides, Phys. Rev. E., 49(2), 1685-1689, 1994.

Rayner, N. A., Brohan, P., Parker, D. E., Folland, C. K., Kennedy, J., Vanicek, M., Ansell, T., and Tett, S. F. B.: Improved analyses of changes and uncertainties in sea-surface temperature measured in situ since the mid-nineteenth century: HadSST2 data set, J. Climate, 19(3), 446-469, 2006.

Reichler, T., Dameris, M., and Sausen R.:Determining the tropopause height from gridded data, Geophys. Res. Lett., 30(20): No. 2042, 2003.

Reid, S. J., Vaughan, G., Mitchell, N. J., Prichard, I. T., Smit, H. J., Jorgensen, T. S., Varotsos, C., and De Backer, H.: Distribution of the ozone laminae during EASOE and the possible influence of inertia-gravity waves, Geophys. Res. Lett., 21, 1479-1482, 1994.

Reid, S. J., Rex, M., von den Gathen, P., Floisand, I., Stordal, F., Carver, G. D., Beck, A., Reimer, E., Kruger-Carstensen, R., De Haan, L. L., Braathen, G., Doronkov, V., Fast, H., Kyro, E., Gil, M. Litynska, Z., Molyneux, M., Murphy, G., O’Connor, F., Ravengani, F., Varotsos, C., Wenger, J., and Zerefos, C.: A study of ozone laminae using diabatic trajectories, contour advection and photochemical trajectory model simulations, J. Atmos. Chem., 30, 187-207, 1998.

Sausen, R., and Santer, B. D.: Use of changes in tropopause height to detect human influences on climate, Meteorologische Zeitschrift, 12(3), 131-136, 2003. 
Seidel, D. J. and Randel, W. J.: Variability and trends in the global tropopause estimated from radiosonde data, J. Geophys. Res., 111, D21101, doi:10.1029/2006JD007363, 2006.

Stanley, E.: Scaling, universality, and renormalization: Three pillars of modern critical phenomena, Rev. Mod. Phys., 71(2), S358S366, 1999.

Steinbrecht, W., Hassler, B., Bruhl, C., Dameris, M., Giorgetta, M. A., Grewe, V., Manzini, E., Matthes, S., Schnadt, C., Steil, B., and Winkler, P.: Interannual variation patterns of total ozone and lower stratospheric temperature in observations and model simulations, Atmos. Chem. Phys., 6, 349-374, 2006, http://www.atmos-chem-phys.net/6/349/2006/.

Talkner, P., and Weber, R. O.: Power spectrum and detrended fluctuation analysis: Application to daily temperatures, Phys. Rev. E., 62(1), 150-160, 2000.

Varotsos, P. A.: Estimate of pressure dependence of dielectric constant in alkali halides, Phys. Status Solidi B, 90, 339-343, 1978.

Varotsos, P. A.: Determination of the composition of the maximum conductivity or diffusivity in mixed alkali halides, J. Phys. Chem. Sol., 42, 405-407, 1981.

Varotsos, P. A., Sarlis, N. V., and Skordas, E. S.: Electric fields that "arrive" before the time-derivative of the magnetic field prior to major earthquakes, Phys. Rev. Lett., 91, 148501, doi:10.1103/PhysRevLett.91.148501, 2003.

Varotsos, C.: Comment on connection between the 11-year solar cycle, the Q. B. O. and the total ozone, J. Atmos. Terr. Phys., 51, 367-370, 1989.

Varotsos, C. A. and Cracknell, A. P.: Ozone depletion over Greece as deduced from nimbus-7 Toms measurements, Int. J. Remote Sens., 14, 2053-2059, 1993.

Varotsos, C. A. and Cracknell, A. P.: Three years of total ozone measurements over Athens obtained using the remote sensing technique of a Dobson spectrophotometer, Int. J. Remote Sens., 15, 1519-1524, 1994.

Varotsos, C., Kondratyev, K. Y., and Katsikis, S.: On the relationship between total ozone and solar ultraviolet radiation at St. Petersburg, Russia, Geophys. Res. Lett., 22, 3481-3484, 1995.
Varotsos, C. A., Kondratyev, K. Y., and Cracknell, A. P.: New evidence for ozone depletion over Athens, Greece, Int. J. Remote Sens., 21, 2951-2955, 2000.

Varotsos, C.: The southern hemisphere ozone hole split in 2002, Environ. Sci. and Pollut. Res., 9, 375-376, 2002.

Varotsos, C.: Atmospheric pollution and remote sensing: implications for the southern hemisphere ozone hole splitnon 2002 and the northern mid-latitude ozone trend, Monitoring of Changes Related to natural and Manmade Hazards Using Space Technology, Adv. Space Res., 33, 249-253, 2004.

Varotsos, C., Cartalis, C., Vlamakis, A., Tzanis, C., and Keramitsoglou, I.: The long-term coupling between column ozone and tropopause properties, J. Climate, 17, 3843-3854, 2004.

Varotsos, C.: Modern computational techniques for environmental data. Application to the global ozone layer. Computational Science - ICCS 2005, PT 3, Lecture Notes in Computer Science, 3516, 504-510, 2005.

Varotsos, C., Ondov, J., and Efstathiou, M.: Scaling properties of air pollution in Athens, Greece, and Baltimore, Maryland, Atmos. Environ., 39(22) 4041-4047, 2005.

Varotsos, C. and Kirk-Davidoff, D.: Long-memory processes in ozone and temperature variations at the region $60 \mathrm{~S}-60 \mathrm{~N}$, Atmos. Chem. Phys., 6, 4093-4100, 2006, http://www.atmos-chem-phys.net/6/4093/2006/.

Varotsos, C. A., Ondov, J. M., Cracknell, A. P., Efstathiou, M. N., and Assimakopoulos, M. N.: Long-range persistence in global Aerosol Index dynamics, Int. J. Remote Sens., 27(16), 35933603, 2006.

Varotsos, C., Assimakopoulos, M. N., and Efstathiou, M.: Technical Note: Long-term memory effect in the atmospheric $\mathrm{CO}_{2}$ concentration at Mauna Loa, Atmos. Chem. Phys., 7, 629-634, 2007, http://www.atmos-chem-phys.net/7/629/2007/.

Weber, R. O. and Talkner, P.: Spectra and correlations of climate data from days to decades, J. Geophys. Res., 106, 20131-20144, 2001.

World Meteorological Organization: Definition of the tropopause, WMO Bull., 6, 136, Geneva, Switzerland, 1957. 